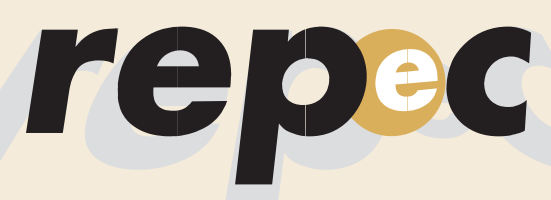

REPeC, Brasília, v. 8, n. 3, art. 1, p. 232-250, jul./set. 2014 Disponível online em www.repec.org.br DOI: http://dx.doi.org/10.17524/repec.v8i3.996
Revista de Educação e Pesquisa em Contabilidade Journal of Education and Research in Accounting Revista de Educación e Investigación en Contabilidad

Periódico Trimestral, digital e gratuito publicado pela Academia Brasileira de Ciências Contábeis

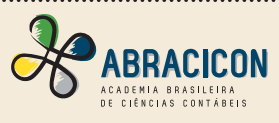

\title{
Análise do Desempenho Socioeconômico de Municípios Gaúchos Emancipados
}

\begin{abstract}
Resumo
O objetivo da pesquisa foi investigar se, estatisticamente, há diferenças no desempenho, nas dimensões financeiras e socioeconômicas de municípios gaúchos emancipados e respectivos municípios de origem. A população ajustada é constituída por 66 municípios, dos quais 25 emancipados e 41 de origem. O desempenho dos municípios é analisado, comparando os indicadores do ano anterior à data de emancipação com os da pós-emancipação. Os indicadores e variáveis selecionados foram coletados nas bases de dados da STN, FEE/RS e IBGE. Os achados da pesquisa, com base na análise global, sugerem que o desempenho dos municípios emancipados não difere, significativamente, dos municípios de origem. Por outro lado, com base na análise individualizada por município e indicador, é preocupante que $92 \%$ dos municípios emancipados apresentam receita própria negativa, refletindo forte dependência dos recursos transferidos pelo estado e pela União. Os indicadores relativos aos gastos com educação, saúde, cultura, saneamento, habitação e urbanização são inferiores nos municípios emancipados. O mesmo ocorre com os outros indicadores financeiros e socioeconômicos.
\end{abstract}

Palavras-chave: Gestão Pública. Emancipação Municipal. Desempenho Socioeconômico.

\begin{abstract}
Marcos Antonio de Souza Doutor em Controladoria e Contabilidade pela Universidade de São Paulo (USP), professor Adjunto da Universidade do Vale do Rio dos Sinos (Unisinos). Contato: Av. Unisinos, 950. Ciências Econômicas. Bairro Cristo Rei. São Leopoldo, RS. CEP.: 93022-000.

E-mail: marcosas@unisinos.br
\end{abstract}

\section{Sabrina Trejes Marengo} Mestre em Ciências Contábeis pela Universidade do Vale do Rio dos Sinos - Unisinos, professor Auxiliar da Universidade do Vale do Rio dos Sinos (Unisinos). Contato: Av. Unisinos, 950. Ciências Econômicas. Bairro Cristo Rei. São Leopoldo, RS. CEP.: 93022-000. E-mail: sabrinamarengo@hotmail.com

\section{Lauro Brito de Almeida}

Doutor em Controladoria e Contabilidade pela Universidade de São Paulo (USP), professor Adjunto da Universidade Federal do Paraná (UFPR). Contato: Av. Pref. Lothário Meissner, $632.1^{\circ}$. Andar , Campus III. Jardim Botânico. Curitiba-PR. CEP.: 80210-170.

E-mail: gbrito@uol.com.br 


\section{Introdução}

A emancipação municipal tem sido tema de discussões no Brasil, originando duas correntes de pesquisadores. De um lado, a corrente formada por especialistas em economia pública (Prado, 2001; Gomes e MacDowell, 2000; Ribeiro, 1998), contrária ao movimento emancipacionista. Essa corrente entende que o movimento emancipacionista cria um excesso de municípios e aumento das despesas com estrutura e serviços das administrações. Para a corrente que reúne os pesquisadores favoráveis às emancipações (Reis Filho, 1997; Ferraz, 1991; Montoro, 1985), essa forma de descentralização administrativa aumenta o poder decisório dos membros das comunidades, melhorando o processo de distribuição das receitas públicas e facilitando o acesso dos cidadãos aos serviços públicos urbanos.

Independente dessas questões, para Tomio (2002), a descentralização política e fiscal tem sido característica da redemocratização brasileira, gerando um expressivo crescimento no número de municípios. Como consequência do processo de descentralização, o Brasil passou de 3.991 municípios em 1980 para 5.565, em 2011. No período de 31 anos, foram criados 1.575 novos municípios, com uma taxa anual de crescimento de 2,81\% (IBGE, 2011).

A criação de novos municípios foi inicialmente regulamentada com a edição do Decreto-Lei Complementar n. ${ }^{\circ}$ 1, de 9/11/1967, posteriormente alterada (Brasil, 1967). A Emenda Constitucional (EC) n. ${ }^{\circ}$ 15/1996 foi indutora da redução das emancipações dos municípios, ao estabelecer por meio da nova redação ao Art. 18 da CF, de 1988, a exigência de elaboração e divulgação prévia do estudo de viabilidade municipal como requisito para obtenção de autorização da consulta plebiscitária. Em 3 de setembro de 2008, a Comissão de Desenvolvimento Urbano (CDU) da Câmara Federal de Deputados emitiu parecer favorável da proposta do PL 1121/2007, referente à regulamentação do $\$ 4^{\circ}$ do Art. 18 da CF. Seguindo o rito, em 4 novembro de 2008, o referido projeto de lei recebeu parecer favorável e foi aprovado pela Comissão de Constituição e Justiça e de Cidadania. No entanto, após quatro anos de trâmite, o PL 1121/2007 foi arquivado, cujo inteiro teor foi publicado no Diário da Câmara dos Deputados (CDC), em $1^{\circ}$ fevereiro de 2011 (CDC, 2011).

A Constituição Federal promulgada em 1988 (CF/88) estabeleceu as medidas de descentralização política e fiscal e foi o mote para que o tema emancipação municipal fosse bastante explorado em estudos científicos. No entanto, para Reis, Figueiras e Oliveira (2010), pelo fato de esses estudos terem sido elaborados em um período próximo à emancipação, não foi possível identificar o real impacto sobre os indicadores socioeconômicos dos municípios emancipados. Há, portanto, carência de estudos com foco na análise das variáveis socioeconômicas dos municípios emancipados. Diante dessa contextualização e uma década após as últimas emancipações, este estudo é orientado pela questão de pesquisa: $\mathbf{O}$ desempenho socioeconômico e financeiro dos municípios gaúchos emancipados difere, comparativamente, de seus municípios de origem?

A relevância e a contribuição do estudo estão em (a) complementar a discussão nas dimensões financeira e socioeconômica dos entes municipais envolvidos nos desmembramentos; (b) prover subsídios relativos à avaliação do desempenho da gestão municipal; (c) contribuir com o avanço científico na área da gestão pública sob o aspecto empírico de movimentos de emancipação municipal. Por fim, o estudo atende à demanda de Reis et al. (2010), para os quais estudos apresentados em eventos científicos já evidenciaram a necessidade da realização de trabalhos que analisem empiricamente os resultados do processo de emancipação municipal.

O artigo está estruturado em cinco seções: inicialmente, esta Introdução, seguida da seção Marco Teórico; a Metodologia, na terceira seção, que discorre sobre o desenho da pesquisa e a abordagem metodológica para o seu desenvolvimento; nas seções seguintes, Resultados e Discussão e Conclusões do estudo. Por fim, em Referências estão listadas as obras consultadas e citadas no estudo. 


\section{Marco Teórico}

\subsection{Avaliação de Desempenho da Gestão Pública}

A mensuração e a avaliação do desempenho, para Guimarães (2008), é uma das ferramentas mais utilizadas para induzir e subsidiar os gestores na condução de uma gestão pública eficiente e comprometida com os resultados. Para Adriano, Pieri e Dutra (2009), as atividades de acompanhar e analisar o desempenho não devem ser privativas somente das organizações com fins lucrativos. Os autores argumentam que, a cada dia, os cidadãos exigem mais transparência e melhoria nos resultados dos órgãos públicos, justificando aprimoramento na avaliação de desempenho dos processos desenvolvidos nos três níveis de governos.

O controle do Estado sobre o alcance das metas envolve a utilização de indicadores de eficiência, eficácia e qualidade (indicadores financeiros, de desempenho operacional, de verificação da consistência da estratégia com ações e programas da organização), para medir o efeito do produto e/ou serviço no cliente-cidadão (Guimarães, 2008). O autor sugere três bases de comparação: (a) em relação ao desempenho da instituição no tempo; (b) em relação ao desempenho de seus pares ou instituições comparáveis; (c) em relação ao que foi planejado para o período. Esta investigação adota como abordagem as duas primeiras bases.

Para Guimarães e Jannuzzi (2004), a pressão social por demandas locais é responsável pela geração e a disseminação periódica de estatísticas, relativas aos indicadores socioeconômicos municipais de desempenho, sobretudo para subsidiar o processo de implantação e monitoramento das políticas públicas. Pollanen (2005) observa que há muitas partes interessadas na avaliação de desempenho (cidadãos, meios de comunicação, representantes eleitos, governo central, agências reguladoras). Essa demanda justifica estudos empíricos sobre o desempenho socioeconômico municipal. Entre os indicadores disponíveis, Jannuzzi (2001) argumenta que a concepção do Índice de Desenvolvimento Humano (IDH) foi marcante diante da necessidade de corrigir as deficiências apontadas nos indicadores chamados de primeira geração. Para o autor, tais indicadores são de natureza econômica bastante restrita e simplória, a exemplo do PIB e PIB per capita. Nesse contexto, o IDH, enquanto indicador, tem o foco de atenção e análise nas pessoas. Assim, as ênfases são para indicadores de desempenho social, composto dos subindicadores de educação, longevidade e renda.

\subsection{Emancipação Municipal}

\subsubsection{Origem e Natureza da Emancipação Municipal}

Refletindo sobre a criação de novos municípios, Paloni (2008) defende o desmembramento como a forma mais comum. No Brasil, conforme o autor, no período de 1998 a 2010, foram criados 1.394 municípios emancipados, caracterizando esse evento como parte de um amplo processo de descentralização. Por outro lado, o processo de emancipação municipal não ocorreu de forma homogênea no país, sendo pouco expressivo em algumas regiões, conforme detalhado na Tabela 1. Embora o maior número de fracionamentos dos entes tenha ocorrido na região Nordeste, foi o Estado do Tocantins, na região Norte, que apresentou a maior taxa de crescimento, considerando o ano-base de 1988. Porém, tomando como base o ano de 1997, as emancipações representam apenas 4,2\% do total de municípios criados. 
Tabela 1

Número de municípios instalados por região no Brasil (1988-2011)

\begin{tabular}{|c|c|c|c|c|c|c|c|c|c|c|c|}
\hline \multicolumn{12}{|c|}{ Municípios } \\
\hline \multirow{2}{*}{ Regiões } & \multirow{2}{*}{$\begin{array}{l}\text { Ano- } \\
\text { Base } \\
1998\end{array}$} & \multicolumn{8}{|c|}{ Instalados } & \multirow{2}{*}{$\begin{array}{l}\text { Total } \\
\text { Geral }\end{array}$} & \multirow{2}{*}{$\begin{array}{c}\text { Taxa } \\
\text { Cresc } \\
\%\end{array}$} \\
\hline & & 1991 & 1993 & 1997 & 2001 & 2003 & 2005 & 2009 & 2010 & & \\
\hline Norte & 195 & 103 & 100 & 51 & 0 & 0 & 0 & 0 & 0 & 449 & 130 \\
\hline Nordeste & 1.476 & 33 & 49 & 229 & 5 & 0 & 1 & 1 & 0 & 1.794 & 22 \\
\hline Centro-Oeste & 329 & 50 & 48 & 19 & 17 & 0 & 3 & 0 & 0 & 466 & 42 \\
\hline Sudeste & 1.418 & 14 & 101 & 133 & 2 & 0 & 0 & 0 & 0 & 1.668 & 18 \\
\hline Sul & 754 & 119 & 185 & 101 & 30 & -1 & 0 & 0 & 1 & 1.189 & 58 \\
\hline Brasil & 4.172 & 319 & 483 & 533 & 54 & -1 & 4 & 1 & 1 & 5.566 & 33 \\
\hline
\end{tabular}

Fonte: Adaptado de Bremaeker (2001) e CNM (2010)

No período analisado, o elevado número de municípios emancipados resultou em um padrão de crescimento desordenado. Nesse contexto, o PL 1.121/2007, caso aprovado, a exigência de elaboração de estudos de viabilidade municipal disciplinaria a criação de novos municípios por meio da emancipação.

\subsubsection{Objetivos do Processo Emancipatório}

O propósito dos estudos realizados na década de 1990 foi entender os motivos indutores da emancipação municipal no Brasil. Nesse contexto, o objetivo da pesquisa realizada por Bremaeker (1993), com prefeitos dos novos municípios, foi identificar os motivos de sua criação. A coleta de dados foi por meio de questionários enviados aos prefeitos dos 581 novos municípios, e a taxa de retorno dos questionários preenchidos e utilizáveis foi de 12,4\%. Com base nos achados da pesquisa, para os prefeitos respondentes, as motivações para a emancipação foram: (i) descaso por parte da administração do município de origem (54,2\%); (ii) existência de forte atividade econômica local (23,6\%); (iii) grande extensão territorial do município de origem (20,8\%); e (iv) aumento da população local (1,4\%).

Seguindo a mesma linha de pesquisa, Noronha (1996) entrevistou a população de 17 municípios emancipados no Estado do Rio de Janeiro entre os anos de 1985 e 1993. Para o autor, com base nos achados da pesquisa, para os munícipes respondentes: (i) a emancipação de sete municípios foi para evitar a estagnação econômica; (ii) seis municípios por possuírem condições econômicas favoráveis; e (iii) quatro municípios por razões políticas ante a tentativa de grupos locais formarem núcleos de poder.

A pesquisa de Cigolini (1999), com 22 municípios paranaenses emancipados na década de 1990, identificou que, para $60 \%$, o principal motivo é a existência de condições econômicas favoráveis. No entanto, Cigolini, com base em estudo posterior, acrescenta que as informações prestadas pelos respondentes podem esconder os reais objetivos dos processos emancipatórios.

Por fim, a pesquisa de Siqueira (2003) também investigou as motivações do processo de emancipação dos municípios. O autor relembra que, até o início de 1980, a criação de municípios acompanhou o avanço da ocupação territorial, em localidades onde se concentravam os maiores índices demográficos e de desenvolvimento econômico. Portanto, argumenta o autor, é necessário analisar isoladamente cada período. 


\subsection{Criação de novos Municípios no Estado do Rio Grande do Sul}

A criação dos primeiros municípios no Estado do Rio Grande do Sul data de 1808/1809. São eles: Porto Alegre (1808), Rio Grande (1809), Rio Pardo (1809) e Santo Antônio da Patrulha (1809). As Tabelas 2 e 3 detalham a criação de municípios por décadas.

Tabela 2

Quantidade de municípios no RS por década (1800-1890)

\begin{tabular}{lcccccccccc}
\hline Municípios & $\mathbf{1 8 0 0}$ & $\mathbf{1 8 1 0}$ & $\mathbf{1 8 2 0}$ & $\mathbf{1 8 3 0}$ & $\mathbf{1 8 4 0}$ & $\mathbf{1 8 5 0}$ & $\mathbf{1 8 6 0}$ & $\mathbf{1 8 7 0}$ & $\mathbf{1 8 8 0}$ & $\mathbf{1 8 9 0}$ \\
\hline Existentes & - & 4 & 5 & 5 & 14 & 20 & 28 & 30 & 48 & 58 \\
\hline Criados & 4 & 1 & 0 & 9 & 6 & 8 & 2 & 18 & 10 & 7 \\
\hline Crescimento \% & 0 & 25 & 0 & 180 & 43 & 40 & 7 & 60 & 21 & 12 \\
\hline
\end{tabular}

Fonte: IBGE (2011); Assembleia Legislativa do RS (2011)

Conforme Tabela 3, somente na década de 1970, não houve criação de municípios no Estado do Rio Grande do Sul. Ao se analisar a região Sul, o Rio Grande do Sul é o estado com maior número de emancipações. No período 1950-1990, foram criados, por meio de emancipações, 405 novos municípios, ou seja, 80\% em relação aos 497 existentes em 2011.

Tabela 3

Quantidade de municípios no RS por década (1900-2010)

\begin{tabular}{lccccccccccccc}
\hline Municípios & 1900 & 1910 & 1920 & 1930 & $\mathbf{1 9 4 0}$ & $\mathbf{1 9 5 0}$ & $\mathbf{1 9 6 0}$ & $\mathbf{1 9 7 0}$ & $\mathbf{1 9 8 0}$ & $\mathbf{1 9 9 0}$ & $\mathbf{2 0 0 0}$ & $\mathbf{2 0 1 0}$ & $\mathbf{2 0 1 1}$ \\
\hline Existentes & 65 & 67 & 71 & 80 & 88 & 92 & 150 & 232 & 232 & 333 & 497 & 496 & 497 \\
\hline Criados & 2 & 4 & 9 & 8 & 4 & 58 & 82 & 0 & 101 & 164 & -1 & 1 & - \\
\hline Cresc. \% & 3 & 6 & 13 & 10 & 5 & 63 & 55 & 0 & 44 & 49 & 0 & 0 & - \\
\hline
\end{tabular}

Fonte: IBGE (2011); Assembleia Legislativa do RS (2011)

Ainda que no período compreendido entre os anos de 2000 e 2010 não tenha havido criação de municípios, não quer dizer que não há demandas. Em setembro de 2011, o Sr. Filipe Madsen Etges, Secretário da Comissão de Assuntos Municipais, Assembleia Legislativa RS (ALRS), ao responder a consulta sobre os pedidos de emancipação, informou que, aproximadamente, 130 distritos protocolaram processos de emancipação.

\subsection{Estudos Relacionados ao Tema}

Entre os estudos nacionais sobre o processo de emancipação dos municípios brasileiros, a investigação conduzida por Siqueira (2003), além revisar o tema com profundidade, organiza os trabalhos em grupos, conforme a abordagem de cada autor. São identificados praticamente todos os trabalhos que analisam as emancipações municipais por subtemas, entre os quais a autonomia municipal e as motivações para as emancipações.

O desempenho socioeconômico de municípios emancipados foi objeto de pesquisa de outra corrente de pesquisadores. Entre os autores, destacam-se Reis, Figueiras e Oliveira (2010), Gonçalves (2010), Costa, Martins, Oliveira e Brunozi Jr. (2009), Guimarães (2008), Jesus (2008) e Lubambo (2006). Em geral, ainda que os achados desses estudos evidenciem os novos municípios com desempenhos inferiores 
aos de origem em algumas variáveis, isso não permite afirmar que as condições não tenham melhorado em relação à situação anterior. Os achados permitem identificar que, em geral, a evolução dos indicadores dos municípios emancipados é menor em relação aos municípios de origem. No âmbito internacional, os estudos localizados não abordam especificamente a emancipação dos municípios e tampouco os demais aspectos pesquisados no Brasil. Em geral, investigam a gestão pública e alguns indicadores, especificamente os relativos à gestão municipal (Fryer, Antony, Ogden, 2009).

\section{Metodologia}

\subsection{População e amostra}

Com base nos dados disponibilizados pela Confederação Nacional de Municípios (CNM), foram identificados 82 municípios envolvidos no movimento de emancipação no período pesquisado. Conforme detalhado na Figura 1, o levantamento computou 30 municípios emancipados em 1996 e instalados, em 2001, e 52 de origem.

\begin{tabular}{|c|c|c|}
\hline Municípios Emancipados & Lei de Criação & Municípios de origem \\
\hline Aceguá & 10.766 & Bagé \\
\hline Arroio do Padre & 10.738 & Pelotas \\
\hline Boa Vista do Cadeado & 10.739 & Cruz Alta, ljuí e Augusto Pestana \\
\hline Bozano & 10.741 & ljuí \\
\hline Canudos do Vale & 10.755 & Lajeado e Progresso \\
\hline Capão Bonito do Sul & 10.742 & Lagoa Vermelha \\
\hline Capão do Cipó & 10.743 & Santiago, São Miguel das Missões e Tupanciretã \\
\hline Coqueiro Baixo & 10.765 & Nova Bréscia e Relvado \\
\hline Coronel Pilar & 10.744 & Garibaldi e Roca Sales \\
\hline Cruzaltense & 10.745 & Campinas do Sul \\
\hline Forquetinha & 10.756 & Lajeado \\
\hline Itati & 10.746 & Terra de Areia \\
\hline Jacuizinho & 10.757 & Salto do Jacuí e Espumoso \\
\hline Lagoa Bonita do Sul & 10.758 & Sobradinho \\
\hline Mato Queimado & 10.747 & Caibaté \\
\hline Novo Xingu & 10.759 & Constantina \\
\hline Paulo Bento & 10.762 & Erechim, Jacutinga, Ponte Preta e Barão de Cotegipe \\
\hline Pinhal da Serra & 10.748 & Esmeralda \\
\hline Quatro Irmãos & 10.761 & Erechim e Jacutinga \\
\hline Rolador & 10.750 & São Luiz Gonzaga \\
\hline Santa Cecília do Sul & 10.763 & Tapejara, Água Santa, Caseiros e Ibiaçá \\
\hline São José do Sul & 10.752 & Salvador do Sul, Montenegro e Maratá \\
\hline São Pedro das Missões & 10.753 & Palmeira das Missões \\
\hline Tio Hugo & 10.764 & Victor Graeff, Ernestina e Ibirapuitã \\
\hline Westfalia & 10.754 & Teutônia e Imigrante \\
\hline
\end{tabular}

Fonte: Confederação Nacional dos Municípios (2010)

Figura 1. Municípios emancipados e seus respectivos municípios de origem 
No entanto, a incompletude de dados nos portais eletrônicos dos municípios impôs a exclusão do ano de 1999. Além disso, dos municípios potencialmente utilizáveis, cinco foram excluídos por falta de informações contínuas nos respectivos portais eletrônicos. Feitos os ajustes necessários na população, na Tabela 4, estão listados 41 municípios de origem e 25 municípios emancipados.

\subsection{Coleta de dados}

Os dados, na categoria de secundários, disponibilizados em relatórios e/ou banco de dados, foram coletados conforme segue: (i) relatórios disponibilizados no Sistema Finanças do Brasil (Finbra) e divulgados pela Secretaria do Tesouro Nacional (STN), (b) documentos divulgados pela Fundação de Estudos Econômicos, RS (FEE/RS) e (c) dados do Instituto Brasileiro de Geografia e Estatística (IBGE). Os dados coletados abarcam as variáveis representativas das condições econômicas e socioeconômicas dos municípios emancipados e de origem instalados no RS. Os grupos de indicadores estão segregados nas dimensões financeira e socioeconômica e detalhados na Figura 2.

\begin{tabular}{|c|c|c|}
\hline Grupos de Indicadores & Indicadores & Fonte \\
\hline Indicadores Financeiros & $\begin{array}{l}\text { 1. Receita Própria versus Receita Corrente } \\
\text { 2. Dívida Ativa versus Receita Corrente } \\
\text { 3. Eficiência Orçamentária } \\
\text { 4. Solvência Geral }\end{array}$ & $\begin{array}{l}\text { STN/Finbra } \\
\text { STN/ Finbra } \\
\text { STN/ Finbra } \\
\text { STN/ Finbra }\end{array}$ \\
\hline $\begin{array}{l}\text { Indicadores } \\
\text { Socioeconômicos }\end{array}$ & $\begin{array}{l}\text { 1. População } \\
\text { 2. Receita (Própria, de Transferência e Total) per capita } \\
\text { 3. Gastos (Educação, Cultura, Saúde, Saneamento, Habitação, Urbanismo, } \\
\text { Função Legislativa e Total) per capita } \\
\text { 4. Receita Tributária per capita } \\
\text { 5. PIB per capita } \\
\text { 6. Índice de Desenvolvimento Socioeconômico (Idese) }\end{array}$ & $\begin{array}{l}\text { IBGE } \\
\text { STN/ Finbra } \\
\text { STN/ Finbra } \\
\text { STN/ Finbra } \\
\text { FEE } \\
\text { FEE }\end{array}$ \\
\hline
\end{tabular}

Fonte: Adaptado de Guimarães (2008)

Figura 2. Dimensões de análise: indicadores financeiros e indicadores socioeconômicos

As variáveis da dimensão socioeconômica utilizadas nessa investigação são as mesmas definidas no estudo de Guimarães (2008). A opção por essas variáveis foi por, além de já terem sido testadas, podem ser aplicadas em qualquer município, independente do porte da população, localização ou área geográfica. Os dados secundários relativos às variáveis de análise, listadas na Figura 2, abrangem para os municípios de origem um ano antes da criação dos municípios emancipados, ou seja um período pré-emancipação e dois períodos pós-emancipação. Para o período pré-emancipação, os dados coletados referem-se ao ano de 2008 e pós-emancipação, os anos de 2009 e 2010.

\subsection{Tratamento e análise dos dados}

Definida a população ajustada e coletados os dados relativos às variáveis da pesquisa, alguns tratamentos iniciais foram necessários. Os valores do PIB per capta foram ajustados a valores constantes de 2009, com base no deflator implícito do PIB. As amostras ou populações ajustadas caracterizam duas amostras independentes - municípios de origem e municípios emancipados e serão comparadas as médias das variáveis dependentes nas dimensões financeira e socioeconômica. De acordo com Malhotra (2006, p. 448), os “[...] testes paramétricos fornecem inferências para fazermos afirmações sobre médias de populações relacionadas. Para esse fim, costuma-se utilizar um teste $t$. Este teste baseia-se na estatística $t$ de 
Student." Na sequência, a aplicação do teste $t$ independente obedeceu às etapas (1) análise individualizada do município emancipado versus município de origem e (2) análise global dos municípios emancipados versus municípios de origem.

\section{Resultados e Discussão}

\subsection{Dimensão Financeira: Análise dos Indicadores Financeiros e Orçamentários}

Para analisar a dimensão financeira dos municípios emancipados em relação aos de origem, com base no estudo de Guimarães (2008), foram selecionados quatro indicadores conforme listados na Figura 2: (1) Receita Própria versus Receita Total; (2) Dívida Ativa versus Receita Corrente; (3) Solvência Geral; e (4) Eficiência Orçamentária.

Os dados coletados no sítio do Sistema do Tesouro Nacional (STN) são calculados e disponibilizados pelo Sistema Finanças do Brasil (Finbra). A análise do desempenho dos municípios emancipados e de origem consiste, inicialmente, em comparar a receita própria dos municípios emancipados do ano 2009 e de 2010. Doravante, os municípios de origem serão nominados mãe e os emancipados filho. O primeiro indicador analisado é "Receita Própria versus Receita Total", conforme detalhado na Tabela 4. Para efeito de análise, foram selecionados os três municípios - mãe e filho - com maiores e menores indicadores de desempenho e comparados.

O indicador "Receita Própria versus Receita Total" fornece um indicativo do quão independente é o município em termos de receitas da União e estado. Quanto maior o indicador, menor a dependência do município às transferências da União e estado, ou seja, em linhas gerais, uma medida de sua eficácia na geração de receitas próprias. Na análise da viabilidade de criação do município, é um indicador crítico.

Tabela 4

Indicador: Receita Própria versus Receita Total

\begin{tabular}{lcccclcccc}
\hline Município & Tipo & $\mathbf{2 0 0 0}$ & $\mathbf{2 0 0 9}$ & $\mathbf{2 0 1 0}$ & Município & Tipo & $\mathbf{2 0 0 0}$ & $\mathbf{2 0 0 9}$ & $\mathbf{2 0 1 0}$ \\
\hline Rolador** & Filho & - & $\mathbf{0 , 0 5 4}$ & $\mathbf{0 , 1 0 3}$ & Progresso & Mãe & 0,153 & 0,253 & 1,009 \\
\hline São Luiz Gonzaga & Mãe & 0,174 & 0,304 & 0,256 & Coqueiro Baixo** & Filho & - & $-1,130$ & $-0,025$ \\
\hline São Pedro das Missões** & Filho & - & 0,022 & 0,093 & Nova Bréscia & Mãe & 0,115 & $-0,022$ & 0,099 \\
\hline Palmeira Missões & Mãe & 0,163 & 0,136 & 0,142 & Relvado & Mãe & 0,080 & $-0,125$ & $-0,098$ \\
\hline Novo Xingu** & Filho & - & $-0,003$ & $-0,032$ & Quatro Irmãos** & Filho & - & $-0,084$ & $-0,127$ \\
\hline Constantina & Mãe & 0,164 & 0,124 & 0,104 & Erechin & Mãe & 0,334 & 0,229 & 0,241 \\
\hline Itati** & Filho & - & $-0,121$ & $-0,018$ & Jacutinga & Mãe & 0,053 & 0,080 & 0,065 \\
\hline Terra de Areia & Mãe & 0,108 & 0,144 & 0,229 & Santa Cecília Sul** & Filho & - & $-0,144$ & $-0,093$ \\
\hline Bozano** & Filho & - & $-0,129$ & $-0,049$ & Água Santa & Mãe & 0,077 & 0,000 & 0,039 \\
\hline ljuí & Mãe & 0,148 & 0,544 & 0,530 & Caseiros & Mãe & 0,080 & 0,061 & 0,130 \\
\hline Canudos do Vale** & Filho & - & $-0,117$ & 0,113 & Ibiaça & Mãe & 0,135 & 0,061 & 0,198 \\
\hline Lajeado & Mãe & 0,293 & 0,240 & 0,217 & Tapejara & Mãe & 0,246 & 0,130 & 0,128 \\
\hline
\end{tabular}

Fonte: Dados da Pesquisa

Os municípios emancipados com maiores desempenhos, em 2009, são Rolador, São Pedro das Missões e Novo Xingu. No extremo, os municípios com menores desempenhos são Santa Cecília do Sul, Coqueiro Baixo e Bozano. Comparando o indicador Receita Própria versus Receita Total, os municípios mãe apresentaram indicadores superiores aos municípios filho. No período analisado, Tabela 4, dos nove municípios filho, 67\% [ $n=6]$ apresentaram aumento no indicador, assim como $73 \%$ [ $n=11]$ dos 15 municípios mãe. 
Com relação ao indicador Dívida Ativa versus Receita Corrente, a Tabela 5 detalha os três municípios, respectivamente filho e mãe, com os maiores e menores indicadores. O objetivo do indicador Dívida Ativa é evidenciar os esforços da administração na cobrança de dívidas fiscais. Por fim, posto que, na sua interpretação, quanto maior o indicador, maior os esforços da gestão nas ações de cobrança, é também uma medida de eficiência e eficácia.

Tabela 5

Indicador: Dívida Ativa versus Receita Corrente

\begin{tabular}{lcccclcccc}
\hline Município & Tipo & $\mathbf{2 0 0 0}$ & $\mathbf{2 0 0 9}$ & $\mathbf{2 0 1 0}$ & Município & Tipo & $\mathbf{2 0 0 0}$ & $\mathbf{2 0 0 9}$ & $\mathbf{2 0 1 0}$ \\
\hline Aceguá** & Filho & - & $\mathbf{0 , 0 5 7}$ & $\mathbf{0 , 0 4 1}$ & Maratá & Mãe & 0,083 & 0,000 & 0,000 \\
\hline Bagé & Mãe & 0,720 & $\mathbf{1 , 0 0 8}$ & $\mathbf{0 , 9 7 8}$ & Montenegro & Mãe & 0,000 & 0,205 & 0,188 \\
\hline Capão do cipó** & Filho & - & 0,031 & $\mathbf{0 , 0 3 4}$ & Salvador do Sul & Mãe & 0,000 & 0,044 & 0,000 \\
\hline Santiago & Mãe & 0,363 & 0,130 & 0,112 & Canudos do Vale** & Filho & - & 0,017 & 0,000 \\
\hline São Miguel Missões & Mãe & 0.095 & 0,063 & 0,035 & Lajeado & Mãe & 0,000 & 0,181 & 0,000 \\
\hline Tupãciretã & Mãe & 0,133 & 0,177 & 0,124 & Progresso & Mãe & 0,016 & 0,037 & 0,000 \\
\hline Forquetinha** & Filho & - & 0,028 & 0,035 & Itati** & Filho & - & 0,000 & 0,000 \\
\hline Lajeado & Mãe & 0,000 & 0,181 & 0,000 & Terra de Areia & Mãe & 0,374 & 0,183 & 0,148 \\
\hline Tio Hugo** & Filho & - & 0,016 & 0,189 & Santa Cecília Sul** & Filho & - & 0,000 & 0,000 \\
\hline Ernestina & Mãe & 0,119 & 0,000 & 0,093 & Água Santa & Mãe & 0,061 & 0,000 & 0,018 \\
\hline Ibirapuitã & Mãe & 0,055 & 0,055 & 0,000 & Caseiros & Mãe & 0,025 & 0,000 & 0,000 \\
\hline Victor Graeff & Mãe & 0,009 & 0,015 & 0,015 & Ibiaça & Mãe & 0,049 & 0,000 & 0,000 \\
\hline São José do Sul** & Filho & - & 0,000 & 0,005 & Tapejara & Mãe & 0,253 & 0,165 & 0,118 \\
\hline
\end{tabular}

Fonte: Dados da Pesquisa

A Tabela 5 detalha municípios com os maiores indicadores Dívida Ativa versus Receita Corrente no ano de 2009, os quais são Aceguá, Capão do Cipó e Forquetinha. Na outra ponta, os municípios com os menores indicadores na gestão da dívida ativa foram Itati, Santa Cecília do Sul e São José do Sul. Em 2010, os municípios com maiores e menores indicadores Dívida Ativa versus Receita Corrente foram, respectivamente: (i) Tio Hugo, Aceguá e Forquetinha e (ii) Canudos do Vale, Itati e Santa Cecília. Ao se analisarem os anos de 2009 e 2010, os municípios Itati e Santa Cecília são reincidentes no grupo de menores indicadores de Dívida Ativa versus Receita Corrente.

Na maioria dos municípios, conforme Tabela 5, no período analisado, o indicador Dívida Ativa versus Receita Corrente é próximo de zero. Esses dados sugerem, para alguns, melhoria não significativa no desempenho; para outros, estagnação; e, também, para outros tantos, piora, ainda que em valores muito pequenos.

Pela ótica da dimensão financeira, o Indicador Eficiência Orçamentária provê os parâmetros para avaliar o desempenho do município na gestão do orçamento. Para interpretar esse indicador, considere que quanto mais distante de zero [maior] pior é o desempenho do município na gestão orçamentária. A Tabela 6 apresenta os três municípios filho com os maiores e menores indicadores de eficiência orçamentária e respectivos municípios mãe. É assumido o pressuposto que não é objetivo do ente público obter superávits significativos, em especial decorrente da economia de recursos, em vez de utilizá-los para gerar benefícios à população. Por outro lado, não é desejável, muito menos prudente adotar práticas de gestão geradoras de déficits, uma indisciplina financeira. Uma gestão saudável resulta em indicadores que evidenciem equilíbrio entre receitas e despesas. 
Tabela 6

Indicador: Eficiência Orçamentária

\begin{tabular}{|c|c|c|c|c|c|c|c|c|c|}
\hline Município & Tipo & 2000 & 2009 & 2010 & Município & Tipo & 2000 & 2009 & 2010 \\
\hline Capão Bonito Sul** & Filho & - & 0,002 & 0,071 & Sobradinho & Mãe & $-0,051$ & $-0,026$ & 0,124 \\
\hline Lagoa Vermelha & Mãe & $-0,035$ & 0,031 & 0,058 & Forquetinha** & Filho & - & 0,116 & $-0,047$ \\
\hline Boa Vista Cadeado** & Filho & - & 0,007 & 0,014 & Lajeado & Mãe & $-0,017$ & $-0,008$ & $-0,045$ \\
\hline ljuí & Mãe & $-0,001$ & $-0,050$ & 0,031 & Santa Cecília Sul** & Filho & - & 0,051 & 0,173 \\
\hline Quatro Irmãos** & Filho & - & 0,050 & 0,000 & Água Santa & Mãe & $-0,016$ & 0,112 & 0,082 \\
\hline Roca Sales & Mãe & $-0,037$ & 0,064 & 0,023 & Caseiros & Mãe & 0,022 & 0,175 & 0,143 \\
\hline Erechin & Mãe & 0,017 & $-0,014$ & 0,020 & Ibiaça & Mãe & 0,061 & 0,020 & 0,168 \\
\hline Jacutinga & Mãe & $-0,001$ & 0,064 & 0,071 & Tapejara & Mãe & $-0,033$ & 0,087 & 0,078 \\
\hline São Pedro Missões** & Filho & - & $-0,021$ & 0,002 & Itati** & Filho & - & $-0,082$ & 0,153 \\
\hline Palmeira Missões & Mãe & 0,032 & 0,132 & 0,088 & Terra de Areia & Mãe & $-0,376$ & 0,072 & 0,031 \\
\hline Rolador** & Filho & - & 0,006 & $-0,003$ & Coronel Pilar** & Filho & - & 0,126 & 0,093 \\
\hline São Luiz Gonzaga & Mãe & $-0,001$ & 0,205 & 0,130 & Garibaldi & Mãe & 0,049 & 0,084 & 0,117 \\
\hline Lagoa Bonita Sul** & Filho & - & $-0,227$ & 0,034 & & & & & \\
\hline
\end{tabular}

Os municípios filho com o melhor desempenho, portanto com os menores indicadores de eficiência orçamentária no ano de 2009, foram Capão Bonito do Sul $(0,002)$, Boa Vista do Cadeado $(0,007)$ e Rolador $(0,006)$. Ainda referente ao ano de 2009, os municípios com os maiores indicadores formam o grupo com o pior desempenho: Lagoa Bonita do Sul $(-0,227)$, Coronel Pilar $(0,126)$ e Forquetinha $(0,116)$. No ano de 2010, a média do indicador de eficiência orçamentária dos municípios foi de 0,030. Ainda, referente ao ano de 2010, o município de Quatro Irmãos apresentou indicador igual a zero (2009), sugerindo, portanto equilíbrio orçamentário. Com indicadores próximos de zero, os municípios de São Pedro das Missões e Rolador completam o grupo de melhor desempenho. Os municípios com os maiores indicadores, portanto formando o grupo com o pior desempenho, foram Santa Cecília do Sul, Itati e Coronel Pilar. Por fim, no ano de 2010, comparando os indicadores de eficiência orçamentária dos municípios filho versus municípios mãe, em geral os municípios filho apresentaram os menores indicadores.

O indicador financeiro de solvência geral, detalhado na Tabela 7 por município mãe e filho, mostra a capacidade financeira do município de pagar as dívidas de curto prazo. Quanto maior o indicador, maior a capacidade de honrar os compromissos e, quanto menor, menor a capacidade de quitar seus débitos. A piora persistente nesse indicador pode resultar em atrasos nos pagamentos aos credores, entre os quais os servidores. Na Tabela 7, estão listados os três municípios com os maiores e menores indicadores de solvência geral, respectivamente para os municípios filho e mãe. 
Tabela 7

Indicador: Solvência geral

\begin{tabular}{|c|c|c|c|c|c|c|c|c|c|}
\hline Município & Tipo & 2000 & 2009 & 2010 & Município & Tipo & 2000 & 2009 & 2010 \\
\hline Capão do Sul** & Filho & - & 0,901 & 0,760 & Jacutinga & Mãe & 0,474 & 0,653 & 1,658 \\
\hline Lagoa Vermelha & Mãe & 0,604 & 0,504 & 0,507 & Ponte Preta & Mãe & 0,704 & 0,664 & 0,644 \\
\hline Capão do Cipó* & Filho & - & 0,750 & 2,293 & Coronel Pilar** & Filho & - & 0,183 & 0,725 \\
\hline Santiago & Mãe & 0,689 & 0,749 & 0,737 & Garibaldi & Mãe & 0,886 & 0,647 & 0,725 \\
\hline São Miguel Missões & Mãe & 0,645 & 0,704 & 0,668 & Roca Sales & Mãe & 0,650 & 0,594 & 0,604 \\
\hline Tupanciretã & Mãe & 0,321 & 0,270 & 0,631 & Forquetinha** & Filho & - & 0,171 & 0,651 \\
\hline Quatro Irmãos** & Filho & - & 0,846 & 0,865 & Lajeado & Mãe & 0,676 & 0,722 & 0,716 \\
\hline Erechim & Mãe & 0,618 & 0,737 & 1,000 & Novo Xingu** & Filho & - & 0,575 & 0,554 \\
\hline Jacutinga & Mãe & 0,474 & 0,653 & 1,658 & Constantina & Mãe & 0,519 & 0,507 & 0,540 \\
\hline Rolador & Filho & - & 1,019 & 0,850 & Arroio do Padre** & Filho & - & 0,483 & 0,495 \\
\hline São Luiz Gonzaga & Mãe & 0,630 & 0,605 & 0,628 & Pelotas & Mãe & 0,555 & 0,422 & 0,500 \\
\hline Paulo Bento & Filho & - & 0,297 & 0,667 & Coqueiro Baixo** & Filho & - & 0,498 & 0,419 \\
\hline Barão do Cotegipe & Mãe & 0,740 & 0,862 & 0,928 & Relvado & Mãe & 0,643 & 0,617 & 0,611 \\
\hline Erechim & Mãe & 0,618 & 0,737 & 1,000 & & & & & \\
\hline
\end{tabular}

Fonte: Dados da Pesquisa

Os municípios filho com maiores indicadores de solvência em 2009 foram Rolador, Capão Bonito do Sul e Quatro Irmãos. Os com menores indicadores de solvência: Paulo Bento, Coronel Pilar e Forquetinha. Em 2010, os municípios Capão do Cipó, Quatro Irmãos e Rolador apresentaram os maiores indicadores de solvência. No geral, os municípios filho apresentaram indicadores de solvência maior que os municípios mãe. Cabe destacar que o município filho Rolador apresentou o maior indicador entre todos, superior a São Luiz Gonzaga.

\subsection{Dimensão Socioeconômico: Análise dos Indicadores Socioeconômicos}

Com base em Guimarães (2008), seis indicadores formam a Dimensão Socioeconômica. Os indicadores PIB per capita por municípios - filho e mãe - estão listados na Tabela 8. 
Tabela 8

Indicador: PIB per capita

\begin{tabular}{lcccc}
\hline \multicolumn{1}{c}{ Municípios } & Tipo & $\begin{array}{c}\text { PIB 2000 a valores } \\
\text { constantes de 2009 }\end{array}$ & $\begin{array}{c}\text { PIB 2008 a valores } \\
\text { constantes de 2009 }\end{array}$ & PIBpc 2009 \\
\hline Pinhal da Serra** & Filho & - & 53.998 & 63.421 \\
\hline Esmeralda & Mãe & 11.491 & 23.381 & 17.853 \\
\hline Boa Vista do Cadeado** & Filho & - & 42.390 & 34.793 \\
\hline Augusto Pestana & Mãe & 9.635 & 19.144 & 17.362 \\
\hline Cruz Alta & Mãe & 12.818 & 22.927 & 23.659 \\
\hline ljuí & Mãe & 15.268 & 18.603 & 18.703 \\
\hline Capão do Cipó** & Filho & - & 34.040 & 30.247 \\
\hline Santiago & Mãe & 8.194 & 9.839 & 9.712 \\
\hline São Miguel das Missões & Mãe & 11.892 & 23.673 & 21.976 \\
\hline Tupanciretã & Mãe & 14.239 & 25.895 & 10.044 \\
\hline Coqueiro Baixo** & Filho & - & 10.726 & 12.840 \\
\hline Nova Bréscia & Mãe & 9.557 & 12.971 & 11.405 \\
\hline Relvado & Mãe & 8.380 & 11.557 & 9.039 \\
\hline Arroio do Padr*** & Filho & - & 8.713 & 11.148 \\
\hline Pelotas & Mãe & 10.708 & 10.932 & 6.366 \\
\hline Itati** & Filho & - & 6.766 & 8.175 \\
\hline Terra de Areia & Mãe & 6.798 & 8.289 & \\
\hline
\end{tabular}

Fonte: Dados da pesquisa

Os municípios devem, entre outros objetivos, implementar políticas que, em geral, resultem em melhoria significativa no padrão de vida dos munícipes, inclusive na geração de renda. Dessa forma, o PIB per capita é uma proxy válida para mensurar o desempenho do município. Portanto, quanto maior o indicador, melhor o desempenho neste quesito.

A Tabela 8 evidencia os municípios filho com os maiores indicadores de PIB per capita (melhores desempenhos) em 2008 e 2009: Pinhal da Serra, Boa Vista do Cadeado e Capão do Cipó. Os municípios filho com os menores indicadores PIB per capita (piores desempenhos) foram Coqueiro Baixo, Arroio do Padre e Itati. Os demais municípios, com exceção de Pinhal da Serra, pioraram nesse indicador.

Ainda de acordo com a Tabela 8, os municípios filho apresentaram indicadores PIB per capita, no período de 2008 e 2009, superiores aos municípios mãe. Se a proposta da emancipação é a melhoria do padrão de vida dos munícipes, medida pela proxy PIB per capita, o desempenho dos municípios filho foi superior aos municípios mãe. Nessa linha de análise, a evolução do PIB per capita do Município de Pinhal da Serra superou o de todos os municípios da amostra.

O Índice de Desenvolvimento Socioeconômico (Idese) tem como objetivo mensurar o desenvolvimento da população nos aspectos socioeconômicos. A mensuração do Idese é com base em uma escala compreendida entre zero e um. A interpretação, com base na escala, como definido no Índice de Desenvolvimento Humano (IDH) classifica os municípios em três níveis de desenvolvimento: (i) baixo (até 0,4999), (ii) médio $(0,500$ a 0,799) e (iii) alto (acima de 0,799$)$. Dessa forma, tomando-se os parâmetros da escala como proxy de desempenho, quanto maior a escala, melhor o desempenho.

Os municípios filho Mato Queimado, Novo Xingu e Rolador, conforme detalhado na Tabela 9, são os com melhores desempenhos no Idese, em 2007, porém não estão no extrato superior da escala alto, acima de 0,799 , e, sim, no nível médio (0,500 a 0,799). 
Tabela 9

Indicador Idese

\begin{tabular}{lcccc}
\hline \multicolumn{1}{c}{ Municípios } & Tipo & Idese 2000 & Idese 2007 & Idese 2008 \\
\hline Mato Queimado** & Filho & - & 0,734 & 0,727 \\
\hline Caibaté & Mãe & 0,704 & 0,750 & 0,749 \\
\hline Novo Xingú** & Filho & - & 0,705 & 0,704 \\
\hline Constantina & Mãe & 0,719 & 0,744 & 0,744 \\
\hline Rolador** & Filho & - & 0,686 & 0,701 \\
\hline São Luiz Gonzaga & Mãe & 0,744 & 0,779 & 0,776 \\
\hline São Pedro das Missões** & Filho & - & 0,585 & 0,597 \\
\hline Palmeira das Missões & Mãe & 0,706 & 0,742 & 0,749 \\
\hline Canudos do Vale** & Filho & - & 0,586 & 0,586 \\
\hline Lajeado & Mãe & 0,754 & 0,783 & 0,786 \\
\hline Progresso & Mãe & 0,600 & 0,624 & 0,633 \\
\hline Arroio do Padre** & Filho & - & 0,578 & 0,585 \\
\hline ljuí & Mãe & 0,768 & 0,806 & 0,806 \\
\hline
\end{tabular}

Fonte: Dados da pesquisa

Classificados como o pior desempenho na escala do Idese estão os municípios filho de São Pedro, Canudos e Arroio do Padre. Ainda, conforme listado na Tabela 9, os municípios mãe apresentaram melhores desempenhos que os municípios filho no período de 2007-2008. Entre os municípios mãe, Ijuí foi classificado de alto nível de desenvolvimento. Todos os municípios mãe foram classificados, conforme escala Idese, nos níveis médio e alto de desenvolvimento.

\subsection{Análise Geral de Desempenho: Municípios Criados versus Municípios de Origem}

A análise geral de desempenho dos municípios criados versus municípios de origem é com base em indicadores compreendidos nas dimensões financeira e socioeconômica. A dimensão financeira contempla os indicadores: (i) Receita Própria versus Receita Total; (ii) Dívida Ativa versus Receita Corrente; (iii) Solvência Geral; e (iv) Eficiência Orçamentária. Na dimensão socioeconômica, foram selecionados os indicadores PIB per capita, Idese, Arrecadação e Gastos.

A Tabela 10 detalha os indicadores tanto da dimensão financeira como da dimensão socioeconômica, relativos à análise geral de desempenho dos municípios emancipados versus municípios de origem. Para efeito de análise geral Municípios Emancipados versus Municípios de Origem, o desempenho foi classificado em: (i) Desempenho Superior; (ii) Desempenho Inferior; e (iii) Desempenho Parcial. 
Tabela 10

Análise geral de desempenho: municípivos emancipados versus municípios de origem

\begin{tabular}{lcccc}
\hline \multirow{2}{*}{ Variáveis de Análise } & \multicolumn{2}{c}{ Desempenho (Emancipados versus Origem) } & \multirow{2}{*}{ Total } \\
\cline { 2 - 4 } & Superior & Inferior & Parcial & \\
\hline IRP - Rec. Própria x Rec. Total & $12 \%$ & $88 \%$ & $0 \%$ & $100 \%$ \\
\hline IDA - Dívida Ativa x Receita Corrente & $12 \%$ & $88 \%$ & $0 \%$ & $100 \%$ \\
\hline IEO - Eficiência Orçamentária & $24 \%$ & $12 \%$ & $64 \%$ & $100 \%$ \\
\hline ISG - Solvência Geral & $44 \%$ & $20 \%$ & $36 \%$ & $100 \%$ \\
\hline Arrecadação & $0 \%$ & $100 \%$ & $0 \%$ & $100 \%$ \\
\hline Gastos & $48 \%$ & $52 \%$ & $0 \%$ & $100 \%$ \\
\hline PIB per capita & $28 \%$ & $40 \%$ & $32 \%$ & $100 \%$ \\
\hline Idese & $0 \%$ & $100 \%$ & $0 \%$ & $100 \%$ \\
\hline
\end{tabular}

Fonte: Dados da Pesquisa

Na escala Desempenho Superior, está indicado o percentual de municípios emancipados com desempenho superior aos de origem nas variáveis analisadas. Na categoria de Desempenho Inferior, é indicado o percentual de municípios emancipados com desempenho menor que os de origem nas variáveis analisadas. Por fim, há aqueles municípios emancipados que alternam o desempenho, ora maiores, ora menores, quando comparados com os de origem e o percentual destes entes está classificado como Desempenho Parcial.

A análise com base no Indicador Receita Própria versus Receita Total [IRP] possibilita uma visão interessante das relações de dependência financeira dos municípios com os estados e União. O quadro geral não deixa de ser preocupante, com reflexos na postura política dos prefeitos ante a forte dependência dos 66 municípios pesquisados (origem $=41$ e emancipados $=25$ ) dos recursos recebidos por transferência da União e estado.

A análise com base no indicador Receita Própria versus Receita Total evidenciou que o desempenho dos municípios de origem foi superior em relação aos emancipados, posto que $88 \%$ [ $n=22$ ] dos municípios emancipados estão na categoria de desempenho inferior aos municípios de origem. Quanto ao desempenho da gestão da dívida, a análise geral do indicador de Dívida Ativa versus Receita Corrente (IDA) evidencia 88\% [ $n=22]$ dos municípios emancipados com desempenho inferior aos municípios de origem.

Com relação à capacidade dos municípios pesquisados de saldarem seus compromissos, a análise do Indicador de Solvência Geral (ISG) evidencia 44\% [ $n=11$ ] dos municípios emancipados com desempenho superior aos de origem. Com desempenho inferior aos de origem, estão $20 \%$ [ $n=5$ ] dos municípios emancipados. Por fim, na categoria desempenho parcialmente superior, estão 36\% [ $n=9$ ] dos municípios emancipados. Cabe observar que, no período analisado, em $56 \%[n=15]$ dos municípios emancipados a gestão dos valores a receber necessita de melhorias gerenciais, com foco na eficiência e eficácia operacional.

A elaboração e o trâmite do orçamento municipal, por vezes, cria um embate entre legislativo e executivo, em geral, com espaços para negociações entre os atores. Porém, ponto igualmente delicado e nevrálgico é sua execução, principalmente tendo em vista os rigores e penalidades impostas aos prefeitos pela Lei de Responsabilidade Fiscal (LRF). Nessa investigação, o indicador de Eficiência Orçamentária (IEO) foi utilizado para avaliar o desempenho da execução orçamentária.

Os dados da Tabela 10 mostram um cenário preocupante quanto ao desempenho da gestão orçamentária dos municípios emancipados comparados aos de origem. Com desempenho inferior, estão $24 \%$ $[n=6]$ dos municípios. Na categoria de desempenho superior, estão $12 \%[n=3]$ municípios, seguido de $64 \%$ [ $n=16]$ em desempenho parcial. Na execução orçamentária, os dados indicam que $76 \%[n=19]$, com base nesse indicador, precisam empreender ações de melhoria, tanto no processo de elaboração como execução do orçamento. 
Para a análise geral de desempenho, na dimensão socioeconômica, foram selecionados os indicadores Arrecadação, Gastos, Idese e PIB per capita. A variável Arrecadação, conforme Tabela 10, indica que a arrecadação dos municípios emancipados $[\mathrm{n}=25]$ foi inferior aos de origem. Por outro lado, analisando-se a receita por tipo (própria, transferência), somente três (equivalente $4,5 \%$ do total [ $n=66]$ e $12 \%$ dos emancipados [ $n=25])$ não apresentam receita própria negativa. No entanto, ainda que positivo na arrecadação, o percentual de receita própria em relação à receita total é baixo. Por outro lado, no que se refere à variável de análise financeira Gastos, em termos globais, 13 [52\%] municípios emancipados apresentam desempenho inferior ao de origem.

A proposta do Idese é ser um indicador da qualidade de vida e das condições econômicas dos munícipes. Nesse sentido, é preocupante o desempenho dos novos municípios, posto que $100 \%$ [ $n=25]$ estão na categoria de inferior quando comparados aos de origem. A análise do PIB per capita dos municípios emancipados mostra 28\% [ $n=7]$ municípios na categoria desempenho superior. No entanto, $40 \%$ [ $n=10]$ e 32\% $[n=8]$ dos municípios emancipados estão categorizados, respectivamente, em desempenho inferior e desempenho parcial. Esses dados sugerem que a melhoria esperada nas condições socioeconômicas para os munícipes de $72 \%$ [ $n=18$ ] demanda que os gestores promovam políticas que, além de melhorar o indicador, mantenha o município no desempenho superior e, principalmente, consistente ao longo do tempo.

\subsection{Análise Global de Desempenho: Municípios Emancipados versus Municípios Origem}

Na criação de novos municípios por meio de emancipação, antes ou depois do evento, as alegações e/ou justificativas mais comuns são: (i) melhoria nas decisões, (ii) melhoria na gestão, (iii) melhoria no atendimento às demandas sociais e (iii) melhoria no padrão de vida dos munícipes.

Está implícita nas alegações e/ou nas justificativas para a emancipação a hipótese de que o novo município, sob outra gestão, será mais eficiente no uso dos recursos e eficaz no atendimento às demandas da população. Considerando que os indicadores nas dimensões financeira e socioeconômica são as proxies do desempenho dos municípios, resta analisar se as médias de seus desempenhos são diferentes e estatisticamente significativas. Para tanto, conforme Tabela 11, serão comparadas as médias dos indicadores, em termos de agregados dos municípios emancipados e de origem, na tabela, respectivamente filhos e mães. 
Tabela 11

Análise Global: médias dos indicadores dos municípios emancipados versus de origem

\begin{tabular}{|c|c|c|c|c|c|}
\hline \multirow[b]{2}{*}{ Variáveis / Ano } & \multicolumn{2}{|c|}{ Média Indicadores } & \multirow[b]{2}{*}{ Variáveis / Ano } & \multicolumn{2}{|c|}{ Média Indicadores } \\
\hline & $\begin{array}{c}\text { Mães } \\
\text { [Origem] }\end{array}$ & $\begin{array}{c}\text { Filhos } \\
\text { [Emancipados] }\end{array}$ & & $\begin{array}{c}\text { Mães } \\
\text { [Origem] }\end{array}$ & $\begin{array}{c}\text { Filhos } \\
\text { [Emancipados] }\end{array}$ \\
\hline RP 2009 & 14,55 & $-8,16$ & Legislativo 2009 & 3,20 & 4,24 \\
\hline RP 2010 & 13,24 & $-6,32$ & Legislativo 2010 & 3,30 & 4,36 \\
\hline RT 2009 & 85,44 & 108,32 & Idese 2007 & 0,734 & 0,650 \\
\hline RT 2010 & 86,75 & 106,32 & Idese 2008 & 0,737 & 0,653 \\
\hline Educação 2009 & 24,44 & 18,92 & PIBpc 2008 & 18.179 & 19.381 \\
\hline Educação 2010 & 26,53 & 20,56 & PICpc 2009 & 17.747 & 18.388 \\
\hline Cultura 2009 & 0,75 & 0,76 & IRP 2009 & 0,152 & $-0,082$ \\
\hline Cultura 2010 & 0,77 & 0,80 & IRP 2010 & 0,164 & $-0,058$ \\
\hline Saúde 2009 & 18,22 & 19,36 & IDA 2009 & 0,140 & 0,012 \\
\hline Saúde 2010 & 19,75 & 20,72 & IDA 2010 & 0,109 & 0,019 \\
\hline Saneamento 2009 & 0,66 & 1,16 & IEO 2009 & 0,073 & 0,001 \\
\hline Saneamento 2010 & 0,68 & 2,12 & IEO 2010 & 0,041 & 0,030 \\
\hline Habitação 2009 & 2,04 & 0,20 & ISG 2009 & 0,621 & 0,634 \\
\hline Habitação 2010 & 3,11 & 0,96 & ISG 2010 & 0,693 & 0,755 \\
\hline Urbanização 2009 & 3,11 & 2,80 & & & \\
\hline Urbanização 2010 & 4,08 & 4,04 & & & \\
\hline
\end{tabular}

A Tabela 11 detalha, nos períodos indicados, as médias dos indicadores nas dimensões financeira e socioeconômica de cada amostra - respectivamente municípios mãe e filho - agregadas nos períodos. Para verificar se há diferenças entre as médias das duas amostras, foi aplicado o teste $t$ independente. Field (2009, p. 287) explica: "O teste $t$ independente é usado em situações nas quais existem duas condições experimentais, e participantes diferentes foram utilizados em cada uma." É o caso dessa investigação, em que temos participantes diferentes - os municípios mãe e filho - e as condições experimentais diferentes para os participantes, no caso, os prefeitos. O software Eviews 5 foi utilizado para processar o teste.

O teste $t$ segue uma distribuição $t$ de Student com n-2 graus de liberdade, onde $n$ indica o número de observações, de forma que, se o valor calculado for maior que o tabelado, rejeita-se a hipótese de que o coeficiente é estatisticamente igual a zero. Uma alternativa ao uso de tabelas estatísticas é a observação do $p$-valor, que fornece a probabilidade de rejeitar a hipótese nula quando ela é verdadeira. Normalmente, considera-se um valor $p$ de 0,05 como o patamar para avaliar a hipótese nula. Se o valor $p$ for inferior a 0,05 , pode rejeitar a hipótese nula.

A análise geral requer comparar as médias das variáveis (indicadores) dos municípios mãe e municípios filho. Para Field (2009, p. 280), "Sob o que é conhecido como hipótese nula, [...] esperamos que as médias das amostras sejam similares." O teste $t$ aplicado aos dados da Tabela 11 resultou um valor $p$ de 0,9598. Em média, o desempenho dos municípios mãe, em termos estatísticos não são significativamente diferentes dos municípios filho, considerando um intervalo de confiança de 95,0\%. Portanto, os resultados sugerem que, não existindo diferenças estatisticamente significativas entre as médias das variáveis analisadas entre os municípios mãe e filho, a criação dos novos municípios nessa modalidade não resultou em melhorias de padrão de vida da população, mensuradas na dimensão socioeconômica e na dimensão gestão financeira. 


\section{Conclusão}

O foco deste estudo foi investigar o desempenho dos municípios gaúchos emancipados versus os de origem, nas dimensões financeira e socioeconômica. Os achados, com base na análise global, sugerem que não há diferenças estatisticamente significativas no desempenho dos municípios gaúchos. Considerando que a criação de novos municípios requer receitas para fazer frente às despesas de custeio e investimentos, os resultados dessa investigação, ainda que limitada pelo horizonte temporal, convergem com a posição daqueles que defendem a necessidade de estudos de viabilidade municipal, como pré-requisito a consulta à população.

É sabido que as decisões de emancipação dos novos municípios não se apoiam em análises técnicas robustas, prevalecendo os aspectos políticos. Sendo o processo conduzido dessa forma, não é de se estranhar a preocupante dependência da maioria dos municípios emancipados (e também dos de origem) das transferências da União e do estado.

Em princípio, destacamos as implicações gerenciais e acadêmicas decorrentes das reflexões sobre os achados da pesquisa. Em termos de implicações gerenciais, os achados permitem elaborar um diagnóstico relativo aos aspectos de eficiência e eficácia na arrecadação (própria e transferências) e aplicações em benefício da população, em especial para os municípios emancipados.

Ainda que as decisões tomadas de emancipação sejam vistas sob um véu político, e carregadas nas tintas da emoção, há profundas implicações financeiras para o estado e a União, como também nas condições econômicas e socioeconômicas dos munícipes. Por exemplo, a grande dependência das transferências do estado e União, além da não melhoria nos padrões socioeconômicos, evidencia que as alegações para emancipação dos municípios não tinham fundamentos.

Pelo lado das implicações acadêmicas, inicialmente, os resultados dessa investigação complementam aspectos não abordados em outros estudos. O resultado da comparação do desempenho dos municípios de origem versus emancipados subsidia a discussão sobre a emancipação com novos elementos e permite aos investigadores contrapor alegações, motivos, promessas, etc., com resultados concretos. Nesse contexto, os achados desta pesquisa possibilitam analisar, identificar e entender quais fatores específicos provocam desempenhos inferiores nos municípios emancipados, quando comparados aos de origem.

Os achados da pesquisa devem ser interpretados com cautela, principalmente ante o horizonte temporal (somente de dois anos) dos dados coletados e, de certa forma, pelo fato de os municípios emancipados estarem ainda em processo de amadurecimento e estruturação da gestão em relação aos de origem. Considerando que o processo de emancipação não é restrito ao Estado do Rio Grande do Sul, esta pesquisa não se esgota em si mesma e proporciona suposições adicionais para novos estudos. A replicação do estudo em outros estados do Brasil viabiliza a construção de uma base de dados para análises comparativas mais abrangentes. Por fim, entende-se que as próximas pesquisas devem valer-se da Teoria dos Locais Centrais e investigar se, após a criação por emancipação dos novos municípios, os de origem não ficaram sobrecarregados, constituindo ponto de atração, inclusive na prestação de serviços dos municípios vizinhos, principalmente os emancipados, sobrecarregando-os com reflexão no atendimento dos seus munícipes.

\section{Referências}

Adriano, A. P.; Pieri Cintia; Dutra, A. (2009). O desempenho dos municípios catarinenses em face da implantação do programa de modernização da administração tributária - PMAT. Anais do Encontro Nacional da Associação Nacional de Pós-Graduação e Pesquisa em Administração, São Paulo, SP, 33.

Assembleia Legislativa do Estado do Rio Grande do Sul. (2011). Consulta ao número de distritos que possuem processos emancipatórios protocolados, Rio Grande do Sul, RS. 
Bremaeker, F. E.(1993). Os novos municípios: surgimento, problemas e soluções. Revista de Administração Municipal, 40(206), pp.88-99.

Bremaeker, F. E. (2001). Evolução do quadro municipal brasileiro no período entre 1980 e 2001. Rio de Janeiro, Instituto Brasileiro de Administração Municipal.

Câmara Federal dos Deputados (CDC), Departamento de Comissões, Coordenação de Comissões Permanentes. (2012). Memorando ${ }^{\circ}$. 612, COPER. Brasília-DF.

Câmara Federal dos Deputados. (2008) Projeto de Leis e Outras proposições. PL 1121/2007, situação arquivada. Recuperado em 24 de março de 2014 de http://www.camara.gov.br/proposicoesWeb/ fichadetramitacao? idProposicao $=352361$

Câmara Federal dos Deputados - CDC. (2011) Arquivamento do PL 1121/2007. Recuperado em 30 de março de 2014 de http://www.camara.gov.br/proposicoesWeb/prop_mostrarintegra?codteor = 1015640\&filename $=$ Tramitacao $-\mathrm{PL}+1121 / 2007$

Cigolini, A. A. (1999). A fragmentação do território em unidades político-administrativas: análise da criação de municípios no estado do Paraná. Dissertação de Mestrado, Universidade Federal de Santa Catarina, Florianópolis, SC, Brasil.

Confederação Nacional dos Municípios. Regulamentação dos estudos de viabilidade municipal. Recuperado em 05 setembro, 2008, de http://portal.cnm.org.br

Confederação Nacional dos Municípios. Consulta criação municípios. Portal Municipal. Recuperado em 11 agosto, 2010, de http://portal.cnm.org.br

Constituição da República Federativa do Brasil de 1988. (1988). Brasília, DF

Costa, I. S.; Martins, S.; Oliveira, A. R.; Brunozi JR, A. C. (2009). Análise dos municípios mineiros emancipados pós-constituição de 1988. Anais da Associação Nacional dos Cursos de Graduação em Administração, Joinville, SC, Brasil, 20.

Fundação de Economia e Estatística. RS Coleta de Dados. Recuperado em 07 novembro, 2011, de http:// www.fee.rs.gov.br/feedados/consulta/sel_modulo_pesquisa.asp

Ferraz, J. F. (1991). Urbis Nostra. São Paulo: Pini.

Field, Andy. (2009). Descobrindo estatística usando SPSS / Andy Field; tradução Lorí Viali. - 2a . ed. - Porto Alegre: Artmed.

Fryer, K.; Antony, J.; Ogden S. (2009). Performance management in the public sector. International Journal of Public Sector Management, 22(6), pp. 478-498.

Fundação Instituto Brasileiro de Geografia e Estatística - IBGE. Vários anos. Censos. Recuperado em 03 julho, 2011, de http://www.ibge.gov.br/home/estatistica/economia/perfilmunic/2011/.

Gomes, G. M; Macdowell, M. C. (2000) Descentralização política, federalismo fiscal e criação de municípios: o que é mau para o econômico nem sempre é bom para o social. IPEA, Texto para Discussão nº. 706, Brasília, DF, Brasil.

Gonçalves, Luciléa F. Lopes. (2010). Emancipações municipais e aplicação de recursos públicos: um estudo de caso no setor educacional em Cinelândia e São Pedro da Água Branca no Maranhão. Dissertação de Mestrado, Universidade Federal do Paraná, Curitiba, PR, Brasil.

Guimarães, S. C. (2008). Avaliação de desempenho da gestão pública municipal. Dissertação de Mestrado, Fundação Getulio Vargas. São Paulo, SP, Brasil.

Guimarães, J. R. S.; Januzzi, P. M. (2004, ). Indicadores sintéticos no processo de formulação e avaliação de políticas públicas: limites e legitimidades. Anais do Encontro Nacional de Estudos Populacionais, Caxambu, MG, Brasil, 14. 
Januzzi, P. M. (2001). Indicadores sociais no Brasil. Campinas: Alínea.

Jesus, Elmo Manuel. (2008). Emancipação municipal: uma estratégia para o desenvolvimento local? O caso de Varzedo/BA. Dissertação de Mestrado. Universidade Estadual da Bahia, Santo Antônio de Jesus, BA, Brasil.

Lei Complementar $n^{\circ}$. 1, de 09/11/1967. Estabelece requisitos mínimos e a forma de consulta prévia às populações locais para a criação de novos municípios. Brasília, DF

Lubambo, C. W. (2006). Desempenho da gestão pública: que variáveis compõem a aprovação popular em pequenos municípios? Sociologias, 8 (16), pp. 86-125.

Malhotra, Naresch. (2006). Pesquisa de marketing: uma orientação aplicada / Naresch Malhotra; tradução Laura Bocco. (4 ed.) Porto Alegre: Bookman.

Ministério da Fazenda. Secretaria do Tesouro Nacional. Finanças do Brasil (FINBRA) - Dados contábeis dos municípios. Recuperado em 20 maio, 2011, de http://www.tesouro.fazenda.gov.br/estatistica

Montoro, F. (1985). A prática da descentralização em São Paulo. Pronunciamento no Congresso Nacional de Vereadores. Brasília, DF, Brasil.

Noronha, R. (1996). Criação de novos municípios: o processo ameaçado. Revista de Administração Municipal, 43(219), pp.110-117.

Paloni, N. A. (2008). O estudo de viabilidade municipal e seu impacto no desenvolvimento nacional. Dissertação de Mestrado, Pontifícia Universidade Católica de São Paulo, São Paulo, SP, Brasil.

Pollanen, R. M. (2005). Performance measurement in municipalities: empirical evidence in Canadian context. International Journal Public Sector Management, 18(1), pp. 4-24.

Prado, S. (2001). Transferências e financiamento municipal no Brasil. Recuperado em 10 janeiro, 2012, de http://www.cepam.sp.gov.br/arquivos/artigos/TransferenciasFiscais\&FinancMunicipal.pdf

Reis, P. R. C.; Figueiras, J. F.; Oliveira, (2010) A. R. Análise comparativa dos indicadores socioeconômicos dos municípios mineiros emancipados após Constituição de 1988 e seus municípios de origem. Anais do Encontro Nacional da Associação Nacional de Pós-Graduação e Pesquisa em Administração, Vitória, ES, Brasil, 26.

Reis Filho, N. G. (1997). Urbanização e urbanismo no Brasil. Cadernos de Pesquisa do LAP,19

Ribeiro, V. L. S. (Coord.) (1998). Conjuntura urbana 2: criação de novos municípios. Secretaria de Política Urbana, Brasília, DF, Brasil.

Siqueira, C. G. (2003). Emancipação municipal pós-constituição de 1988: um estudo sobre o processo de criação dos novos municípios paulista. Dissertação de Mestrado, Universidade Estadual de Campinas. Campinas, SP, Brasil.

Tomio, F. R. L. (2002). A criação de municípios após a Constituição de 1988. Revista Brasileira de Ciências Sociais, 17(48), pp. 61-89. 